\title{
Damage Analysis of Aluminium Foam Panel Subjected to Underwater Shock Loading
}

\author{
Xuan He, Ji-li Rong, and Da-lin Xiang \\ School of Aerospace Engineering, Beijing Institute of Technology, Beijing 100081, China \\ Correspondence should be addressed to Ji-li Rong; rongjili@bit.edu.cn
}

Received 28 June 2016; Revised 18 November 2016; Accepted 28 November 2016; Published 28 February 2017

Academic Editor: Fiorenzo A. Fazzolari

Copyright (C) 2017 Xuan He et al. This is an open access article distributed under the Creative Commons Attribution License, which permits unrestricted use, distribution, and reproduction in any medium, provided the original work is properly cited.

\begin{abstract}
Underwater shock loading experiment device is the equipment which simulates underwater explosive shock wave through experiment. Underwater shock loading experiment device was used to conduct high-speed underwater impact on aluminium foam panel and its damage modes were studied in this paper. 3D dynamic DIC test system was used to collect and analyze realtime deformation of target board. After the experiment was completed, a numerical simulation of the series of experiment was conducted through ABAQUS finite element simulation and then a comparative analysis of the experiment was implemented. To comprehensively study damage modes of aluminium foam panel subjected to underwater shock loading, damage modes of aluminium foam panel at different shock speeds were studied. Results indicated that when a certain impact speed which could damage aluminium foam panel was reached, if the impact speed was low, aluminium foam panel would generate shear fracture at constrained boundary of flange; if the impact speed was high, aluminium foam panel would firstly generate fracture at the center and then generate shear fracture at constrained boundary of flange, and central fracture would generate three cracks.
\end{abstract}

\section{Introduction}

Cellular materials, such as foams, are important lightweight materials to resist impact. Nowadays, more and more attention has been paid to these materials [1-4]. Aluminium foam is produced through foaming process after additive is added into pure aluminium or aluminium alloy. It has both metal and bubble characteristics. It is of low density, high energy absorbability, high-temperature resistance, strong fireproof performance, and so on. Aluminium foam has extensive development prospect in industries of aerospace, transportation, architectural structure, and so on. Mechanical properties of aluminium foam are the most fundamental and important properties. Deshpande and Fleck $[5,6]$ studied the properties of aluminium foam at high strain rate. They found that aluminium foam was basically rate-independent material, and then they proposed isotropic constitutive equations of aluminium foam. Mukai et al. [7] found that closedcell aluminium foam was of obvious strain rate effect in use of SHPB device. Paul and Ramamurty [8] also found that closed-cell aluminium foam under normal temperature was sensitive to strain rate. Dannemann and Lankford Jr. [9] conducted relevant studies of closed-cell aluminium foam and found that strain rate of aluminium foam with relatively higher density was more obvious. Radford et al. [10] studied the response of sandwich plate of aluminium foam subjected to shock loading.

Deshpande et al. [11, 12] theoretically analyzed a cylindrical FSI device and subsequently studied the properties of foam core material under impact loading. Espinosa et al. [13] designed a novel fluid-structure interaction (FSI) experiment with divergent diffuser and generated the equivalent underwater explosion shock wave loading in a tapered water tank, in which a flyer impacted the piston at high speed at the entrance of the water tank. The flyer was driven by a light gas gun (LGG). Mori et al. [14, 15] explored the deformation and energy absorption characteristics of lightweight lattice materials under the impact loading of underwater explosion by using the device designed by Espinosa et al. Latourte et al. [16] tested the deformation and fracture characteristics of the designed steel alloys experimentally and computationally with the FSI apparatus. Latourte et al. [17] and Wei et al. 
[18] investigated the failure modes, damage mechanisms, and deformation of both monolithic and sandwich composite panels subjected to underwater impulsive loads with FSI equipment. Similarly, by using the FSI apparatus, Tran et al. [19] redesigned a composite panel and investigated the performances of the bioinspired composite panel subjected to underwater impulsive loads. Xiang et al. [20] investigated the dynamic response and deformation of aluminium honeycomb sandwich panels subjected to underwater impulsive loads. Based on these related studies, the current exploration of FSI devices has become the research hotspot.

Damage characteristic is an important property of aluminium foam. However, most studies conducted were subjected to shock loading in air [21, 22], and few studies were about damage mode of aluminium foam subjected to underwater shock load. In this paper, the damage of aluminium foam panels subjected to underwater shock loadings was studied. By considering the work of Espinosa et al. [13], an underwater shock loading experimental device was constructed. A series of experiments was conducted on the aluminium foam panels with this device. Then ABAQUS/ EXPLICIT was used to simulate the experiments. The simulation result agrees well with the experiments. Based on the result of simulation and experiment, the damage modes of aluminium foam panels subjected to underwater shock loading are researched and analyzed.

\section{Experiment and Theoretical Foundations}

2.1. Underwater Shock Loading Experiment Device. Underwater shock loading experiment device is shown in Figure 1, and its core part is a water tank. Inside the water tank is a conical cavity at the left. During the experiment, the water tank is filled with water. The flyer is driven by a primary light gas gun (LGG). The stress wave is generated when the flyer impacts the piston. Then stress wave will repeatedly project and reflect on the interface between piston and water, and the shock wave is formed inside water tank. The shock wave spreads forward and finally acts on target board.

The schematic diagram of water tank is shown in Figure 2. Diameters of two ends of cavity in water tank are, respectively, $152.4 \mathrm{~mm}$ and $66 \mathrm{~mm}$. Outer diameter of the water tank is $292 \mathrm{~mm}$. A $76 \mathrm{~mm}$ long cylindrical cavity is linked to the smaller end of the water tank. And it gradually connects with the tapered cavity at an angle of $7^{\circ}$. There are three installation holes for sensors at side wall of the water tank. The underwater shock wave pressure can be measured through the sensor in these holes. Target board is fixed by a flange at the larger end of the water tank. The inner diameter of flange is $152.4 \mathrm{~mm}$, which is identical with the inside diameter of the water tank's larger end. The thickness of flange is $25.4 \mathrm{~mm}$, and it is manufactured by $42 \mathrm{CrMu}$ steel. Both of its strength and stiffness are large enough to guarantee that target board deformation will not be influenced. Speed of the flyer is measured by a laser velocimeter.

2.2. High-Speed Camera Shooting System. VIC-3D digital image processing software developed by US CSI Corporation

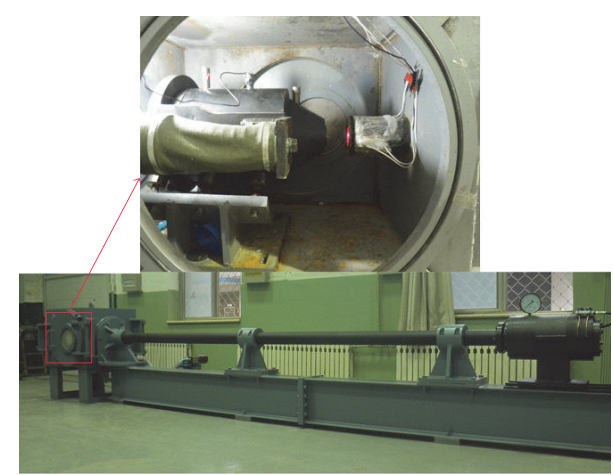

FIGURE 1: Underwater shock loading experiment device.

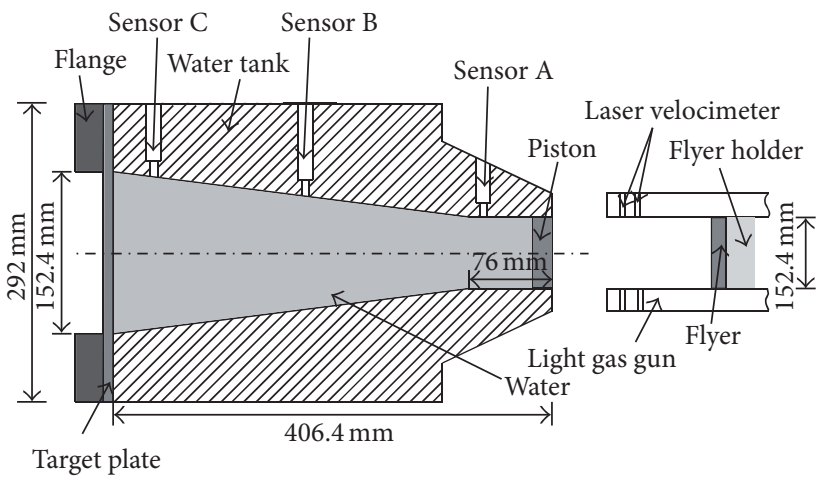

FIGURE 2: Schematic diagram of underwater shock loading experiment device.

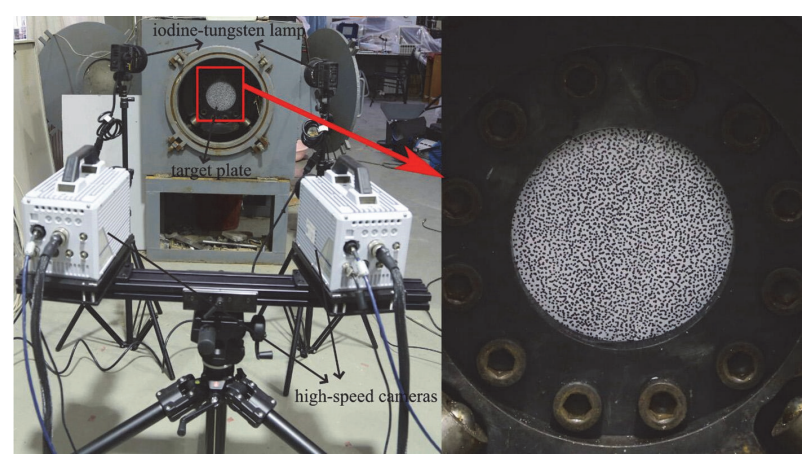

FIgURe 3: 3D dynamic DIC test system.

was used in the experiment. The 3D dynamic DIC test system was used to measure full-field deformation of target board.

3D dynamic DIC test system includes two high-speed cameras and iodine-tungsten lamp light source as shown in Figure 3. The angle between two cameras was about $20^{\circ}$, and each camera was about $2 \mathrm{~m}$ away from tested target board. Camera shooting velocity was 50,000 frames/s in the experiment. Luminance and position of light source were adjusted to ensure that the shoot image was bright enough without light reflection. So deformation of speckles on target board could be calculated. 


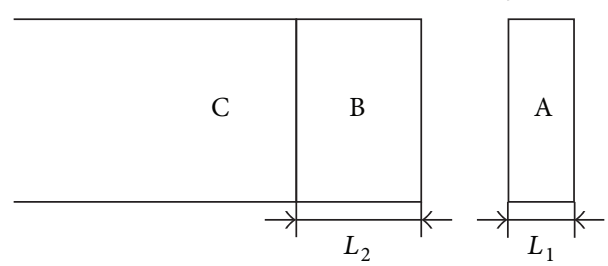

FIGURE 4: Schematic diagram of flyer, piston, and water.

2.3. Theoretical Analysis. According to stress wave theory, the situation in which water tank was cylindrical was firstly taken into consideration. Flyer, piston, and water were simplified into a system as shown in Figure 4, where A was flyer, B was piston, and $\mathrm{C}$ was water. Flyer and piston were of the same material; their wave impedance was noted as $\left(\rho_{0} C_{0}\right)_{1}$, and that of water was noted as $\left(\rho_{0} C_{0}\right)_{2}$.

When $\mathrm{A}$ impacted $\mathrm{B}$, particle velocity and pressure were the same and were, respectively, expressed as follows:

$$
\begin{aligned}
& u_{p}=\frac{v_{1}}{2} \\
& p_{0}=-\frac{\left(\rho_{0} C_{0}\right)_{1} v_{1}}{2} .
\end{aligned}
$$

It's assumed that $L_{2}>2 L_{1}$, when $t=2 L_{1} /\left(C_{0}\right)_{1}$; a stress wave with a length of $2 L_{1}$ was generated at right end of $\mathrm{B}$. At the moment, particle velocity and pressure in A were zero, and A stopped motion. A would not be taken into consideration in the subsequent analysis.

When $t=L_{2} /\left(C_{0}\right)_{1}$, stress wave in $\mathrm{B}$ reached contact surface between $\mathrm{B}$ and $\mathrm{C}$. At the moment, only a stress wave with a length of $2 L_{1}$ was transmitted in $\mathrm{B}$; $\mathrm{C}$ had neither pressure nor velocity. According to the superposition of stress wave reflection and transmission, the intensity of reflected wave was expressed as follows:

$$
p_{r 1}=\frac{\left(\rho_{0} C_{0}\right)_{1}-\left(\rho_{0} C_{0}\right)_{2}}{\left(\rho_{0} C_{0}\right)_{1}+\left(\rho_{0} C_{0}\right)_{2}} p_{0}
$$

The intensity of the transmitted wave was expressed as follows:

$$
p_{t 1}=\frac{2\left(\rho_{0} C_{0}\right)_{2}}{\left(\rho_{0} C_{0}\right)_{1}+\left(\rho_{0} C_{0}\right)_{2}} p_{0}=-\frac{\left(\rho_{0} C_{0}\right)_{1}\left(\rho_{0} C_{0}\right)_{2}}{\left(\rho_{0} C_{0}\right)_{1}+\left(\rho_{0} C_{0}\right)_{2}} v_{1} .
$$

Duration of this transmitted wave was $\Delta t_{1}=2 L_{1} /\left(C_{0}\right)_{1}$.

Then after duration time $\Delta t_{2}=\left(2 L_{2}-2 L_{1}\right) /\left(C_{0}\right)_{1}$ (within this period, intensity of stress wave on contact surface between $\mathrm{B}$ and $\mathrm{C}$ was 0 ); reflected wave with a length of $2 L_{1}$ and intensity of $p_{r 1}$ reached contact surface between $B$ and $C$. The intensity of the reflected wave was expressed as follows:

$$
p_{r 2}=\frac{\left(\rho_{0} C_{0}\right)_{1}-\left(\rho_{0} C_{0}\right)_{2}}{\left(\rho_{0} C_{0}\right)_{1}+\left(\rho_{0} C_{0}\right)_{2}} p_{r 1}
$$

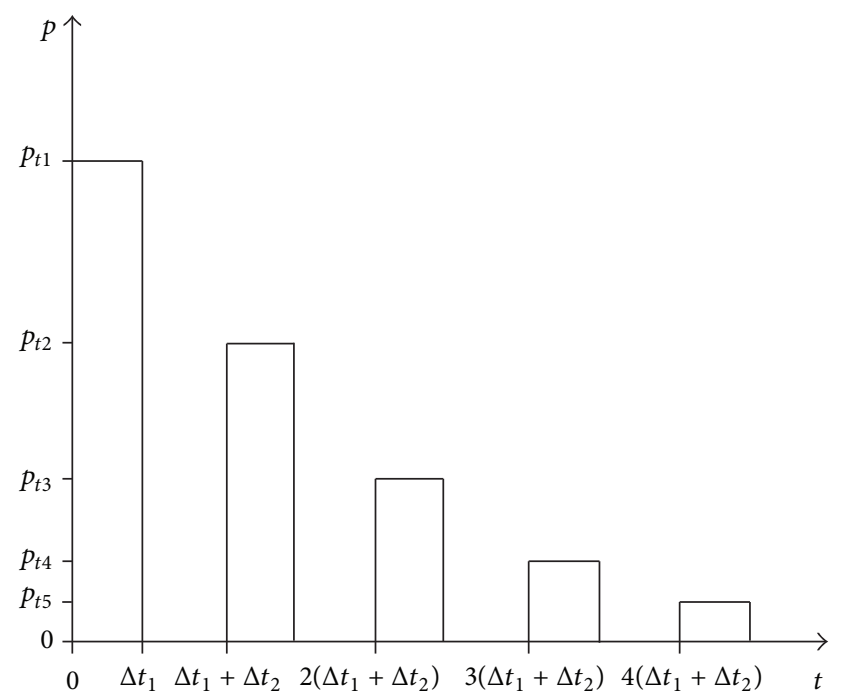

FIGURE 5: Schematic diagram of pressure-time history.

The intensity of transmitted wave was expressed as follows:

$$
\begin{aligned}
p_{t 2} & =\frac{2\left(\rho_{0} C_{0}\right)_{2}}{\left(\rho_{0} C_{0}\right)_{1}+\left(\rho_{0} C_{0}\right)_{2}} p_{r 1} \\
& =-\frac{\left(\rho_{0} C_{0}\right)_{1}\left(\rho_{0} C_{0}\right)_{2}}{\left(\rho_{0} C_{0}\right)_{1}+\left(\rho_{0} C_{0}\right)_{2}} \frac{\left(\rho_{0} C_{0}\right)_{1}-\left(\rho_{0} C_{0}\right)_{2}}{\left(\rho_{0} C_{0}\right)_{1}+\left(\rho_{0} C_{0}\right)_{2}} v_{1} .
\end{aligned}
$$

In this analogy, when the $N$ th stress wave reached contact surface between B and C, the pressure in C was expressed as follows:

$p_{t N}$

$$
=-\frac{\left(\rho_{0} C_{0}\right)_{1}\left(\rho_{0} C_{0}\right)_{2}}{\left(\rho_{0} C_{0}\right)_{1}+\left(\rho_{0} C_{0}\right)_{2}} v_{1}\left[\frac{\left(\rho_{0} C_{0}\right)_{1}-\left(\rho_{0} C_{0}\right)_{2}}{\left(\rho_{0} C_{0}\right)_{1}+\left(\rho_{0} C_{0}\right)_{2}}\right]^{N-1} .
$$

The duration of each $p_{t N}$ was $\Delta t_{1}=2 L_{1} /\left(C_{0}\right)_{1}$. Then during the process of $\Delta t_{2}=\left(2 L_{2}-2 L_{1}\right) /\left(C_{0}\right)_{1}$, the pressure was zero. The pressure-time history was shown in Figure 5.

For the conical water tank, it is assumed that shock wave transmission process abided by momentum conservation, and the pressure at measuring point could be expressed as

$$
\begin{aligned}
p_{\text {point }} & =p_{t N}\left(\frac{D_{0}}{D}\right)^{2}=-\left(\frac{D_{0}}{D}\right)^{2} \frac{\left(\rho_{0} C_{0}\right)_{1}\left(\rho_{0} C_{0}\right)_{2}}{\left(\rho_{0} C_{0}\right)_{1}+\left(\rho_{0} C_{0}\right)_{2}} \\
\cdot v_{1} & {\left[\frac{\left(\rho_{0} C_{0}\right)_{1}-\left(\rho_{0} C_{0}\right)_{2}}{\left(\rho_{0} C_{0}\right)_{1}+\left(\rho_{0} C_{0}\right)_{2}}\right]^{N-1}, }
\end{aligned}
$$

where $D_{0}$ was the diameter of the entrance of conical water tank and $D$ was the inner diameter of water tank at measuring point. All minus signs in the above formulas represented that stress wave was compression wave. 
If $N=1$, the pressure, which was the maximum, was called the peak pressure. The peak pressure at measuring point could be expressed as follows:

$$
p_{m}=-\left(\frac{D_{0}}{D}\right)^{2} \frac{\left(\rho_{0} C_{0}\right)_{1}\left(\rho_{0} C_{0}\right)_{2}}{\left(\rho_{0} C_{0}\right)_{1}+\left(\rho_{0} C_{0}\right)_{2}} v_{1} .
$$

Therefore, the pressure of measuring point could be expressed as

$$
\begin{aligned}
p_{\text {point }} & =p_{m}\left[\frac{\left(\rho_{0} C_{0}\right)_{1}-\left(\rho_{0} C_{0}\right)_{2}}{\left(\rho_{0} C_{0}\right)_{1}+\left(\rho_{0} C_{0}\right)_{2}}\right]^{N-1} \\
= & p_{m} \\
& \cdot e^{-t /\left[2 L_{2} /\left(C_{0}\right)_{1} \ln \left(\left(\left(\rho_{0} C_{0}\right)_{1}+\left(\rho_{0} C_{0}\right)_{2}\right) /\left(\left(\rho_{0} C_{0}\right)_{1}-\left(\rho_{0} C_{0}\right)_{2}\right)\right)\right]} .
\end{aligned}
$$

The decay time constant could be expressed as

$\theta$

$$
=\frac{2 L_{2}}{\left(C_{0}\right)_{1} \ln \left(\left(\left(\rho_{0} C_{0}\right)_{1}+\left(\rho_{0} C_{0}\right)_{2}\right) /\left(\left(\rho_{0} C_{0}\right)_{1}-\left(\rho_{0} C_{0}\right)_{2}\right)\right)} .
$$

2.4. Experimental Samples. Target board used in the experiment was aluminium foam panel with the thickness of $14 \mathrm{~mm}$ and the density of $0.3 \mathrm{~g} / \mathrm{cm}^{3}$. The manufacturer of the aluminium foam was Shanxi Putai Aluminum Foam Manufacturing Co., Ltd., in China. The processed aluminium foam panel was shown in Figure 6. Quasi-static compression experiment was conducted to obtain the nominal stressstrain curve. It was shown in Figure 7. The constitutive model of aluminium foam was plastic hardening model:

$$
\begin{aligned}
\sigma_{\text {true }} & =\sigma_{\text {nom }} \\
\varepsilon_{\text {true }} & =-\ln \left(1-\varepsilon_{\text {nom }}\right) \\
\varepsilon_{\mathrm{pl}} & =\varepsilon_{\text {true }}-\frac{\sigma_{\text {true }}}{E},
\end{aligned}
$$

where $\varepsilon_{\text {nom }}$ was nominal strain, $\sigma_{\text {nom }}$ was nominal stress, and $\varepsilon_{\mathrm{pl}}$ was plastic strain.

As speckles could not be made on the surface of aluminium foam panel, an aluminium face sheet was added in the front of the aluminium foam panel and then speckles were made on the aluminium face sheet. In the experiment, another aluminium face sheet was also added at the back of the aluminium foam panel to prevent water from flowing out of the aluminium foam panel. Schematic diagram of aluminium foam panel and aluminium face sheets was shown in Figure 8. The material of face sheet was 3004 aluminium. Its constitutive equation was simulated through JohnsonCook constitutive model [23]:

$$
\sigma(t)=\left(A+B \varepsilon^{n}(t)\right)\left[1+C \ln \left(\frac{\dot{\varepsilon}(t)}{\dot{\varepsilon}_{0}(t)}\right)\right]\left(1-t_{*}^{m}\right),
$$

where $\varepsilon(t)$ was plastic strain, $\dot{\varepsilon}(t)$ was strain rate, $\dot{\varepsilon}_{0}(t)$ was the reference strain rate, $t_{*}^{m}=\left(t-t_{r}\right) /\left(t_{m}-t_{r}\right), t_{r}$ was room temperature, and $t_{m}$ was melting point. The material parameters were shown in Table 1.

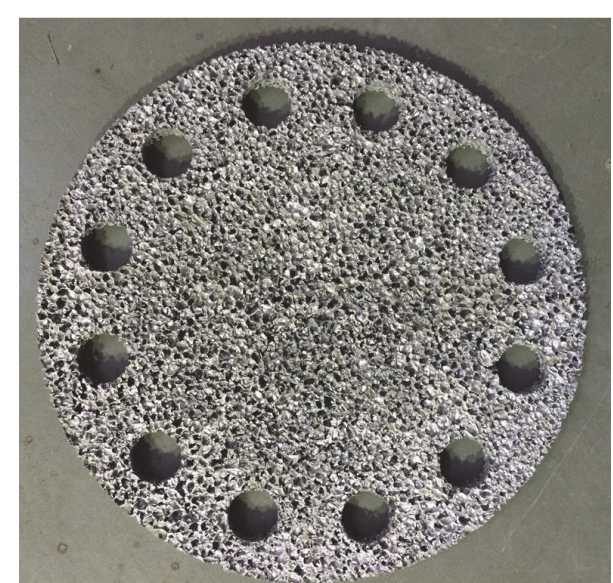

Figure 6: The processed aluminium foam panel.

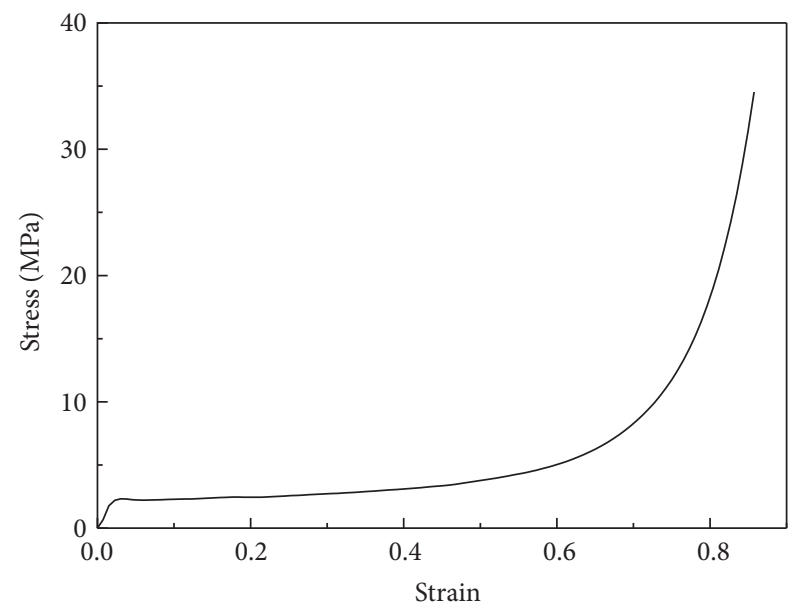

FIGURE 7: The nominal stress-strain curve of aluminium foam.

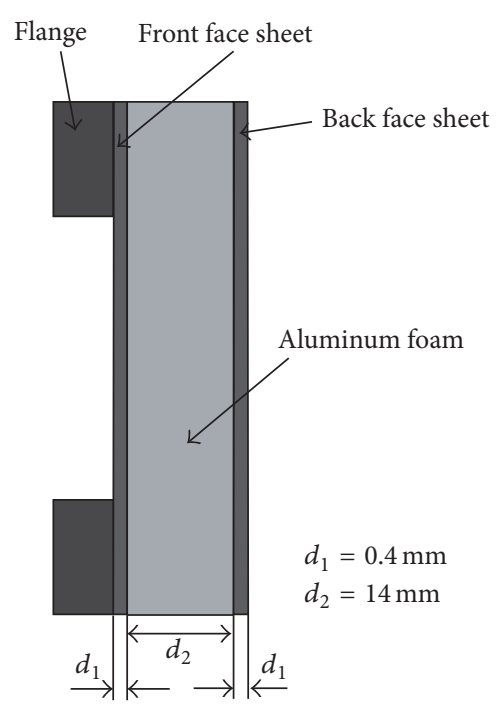

FIGURE 8: The schematic diagram of aluminium foam panel and aluminium face sheets. 
TABLE 1: Material properties of 3004 aluminium.

\begin{tabular}{|c|c|c|c|c|c|c|c|c|c|}
\hline & Density $/ \mathrm{g} \cdot \mathrm{cm}^{-3}$ & $\begin{array}{l}\text { Young's } \\
\text { modulus } \\
E / \mathrm{MPa}\end{array}$ & $\begin{array}{c}\text { Poisson's } \\
\text { ratio } \\
v\end{array}$ & $A / \mathrm{MPa}$ & $B / \mathrm{MPa}$ & C & $n$ & $m$ & $t_{m} / \mathrm{K}$ \\
\hline $3004 \mathrm{Al}$ & 2.7 & 70000 & 0.3 & 127 & 282.55 & 0.0832 & 0.44 & 2.09 & 933 \\
\hline
\end{tabular}

TABLE 2: Material properties of steel4340 and steel 4140.

\begin{tabular}{lcccccc}
\hline & $\begin{array}{c}\text { Young's } \\
\text { modulus/GPa }\end{array}$ & $\begin{array}{c}\text { Poisson's } \\
\text { ratio }\end{array}$ & Density/kg.m ${ }^{-3}$ & Yield stress/MPa & $\begin{array}{c}\text { Hardening } \\
\text { coefficient/MPa }\end{array}$ & Hardening exponent \\
\hline STEEL 4340 & 205 & 0.29 & 7850 & 470 & 470 & 0 \\
STEEL 4140 & 205 & 0.29 & 7850 & 1000 & 1615 & 0.09 \\
\hline
\end{tabular}

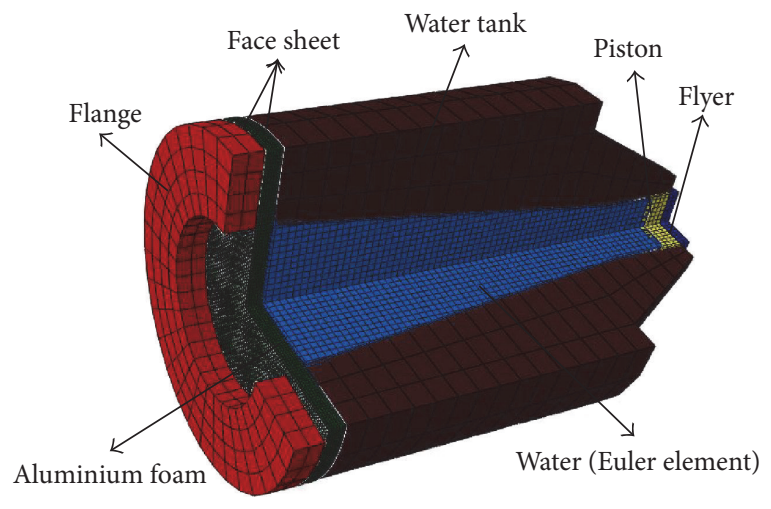

Figure 9: The finite element model of ABAQUS.

\section{Finite Element Simulation}

ABAQUS software was used to conduct numerical simulation of underwater shock loading experiment device. The model was shown in Figure 9. Water tank and flange were simulated by STEEL4340 (40CrNiMoA) structural alloy steel. Piston and flyer were simulated by STEEL4140 (30CrMo) structural alloy steel after quench hardening. The material parameters were shown in Table 2.

As the strength and stiffness of water tank, flange, piston, and flyer were high, their deformation was little during computing process. So the mesh dividing these parts was relatively rough. There were totally 3,096 meshes in these parts. There were 32,256 meshes in front and back face sheets, 55,896 ones in aluminium foam panel, and 54,756 ones in water (Euler area).

The flange and water tank were fixed and they could not be moved and rotated. The front face sheet was tied to flange and the back face sheet was tied to water tank. The type of constraint between face sheets and foam core was Contact, which was the same as that in the experiment. The constraints between water tank, piston, and flyer were also Contact. Fluid-structure interaction was used to define the interaction between water and solid. In simulation, the aluminium foam was set as a solid structure, instead of a porous structure. Therefore, when the water contacted foam core, the interaction between water and aluminium foam was also defined as fluid-structure interaction.
The failure criterion of aluminium face sheet was used Ductile Damage criterion in ABAQUS. As the failure conditions must be unified between different materials, Ductile Damage criterion was also used to simulate the damage effect of aluminium foam. Damage parameters were set as follows:

$$
\begin{array}{ll}
0.8, & -0.33 \\
0.004, & 0 \\
0.005, & 0.33 \\
0.008, & 0.66
\end{array}
$$$$
{ }^{*} \text { Damage Initiation, criterion }=\text { DUCTILE }
$$

\section{Results and Discussion}

Different damage modes of aluminium foam panel were researched at two different flyer speeds.

Xue and Hutchinson [24] gave a nondimensionalized impulse $\widehat{I}$ to assess the shock loading applied to target board:

$$
\widehat{I}=\frac{I_{0}}{\bar{M} \cdot \sqrt{\sigma_{y} / \rho}}
$$

where $\bar{M}$ was the mass of target board in unit area, $\bar{M}=$ $4.2 \mathrm{~kg} / \mathrm{m}^{2} ; \sigma_{y}$ was the yield stress, $\sigma_{y}=2.3 \mathrm{MPa} ; \rho$ was the density of target board, $\rho=300 \mathrm{~kg} / \mathrm{m}^{3} ; I_{0}$ was the impulse when shock wave reached target board, $I_{0}=p_{m} \theta$. It could be known from formulas (9) and (11) that

$$
p_{m}=-\left(\frac{D_{0}}{D}\right)^{2} \frac{\left(\rho_{0} C_{0}\right)_{1}\left(\rho_{0} C_{0}\right)_{2}}{\left(\rho_{0} C_{0}\right)_{1}+\left(\rho_{0} C_{0}\right)_{2}} v_{1}=0.2658 v_{1} \mathrm{MPa}
$$

$\theta$

$$
=\frac{2 L_{2}}{\left(C_{0}\right)_{1} \ln \left(\left(\left(\rho_{0} C_{0}\right)_{1}+\left(\rho_{0} C_{0}\right)_{2}\right) /\left(\left(\rho_{0} C_{0}\right)_{1}-\left(\rho_{0} C_{0}\right)_{2}\right)\right)}
$$$$
=0.129 \mathrm{~ms} \text {. }
$$

When the flyer speed was $v_{1}=135.06 \mathrm{~m} / \mathrm{s}$ and $\widehat{I}=$ 12.6, aluminium foam panel generated shear fracture at constrained boundary of flange; when flyer speed was $v_{1}=$ $153.33 \mathrm{~m} / \mathrm{s}$ and $\widehat{I}=14.3$, aluminium foam panel generated fracture in the center region and then generated boundary shear fracture at constrained boundary of flange. 


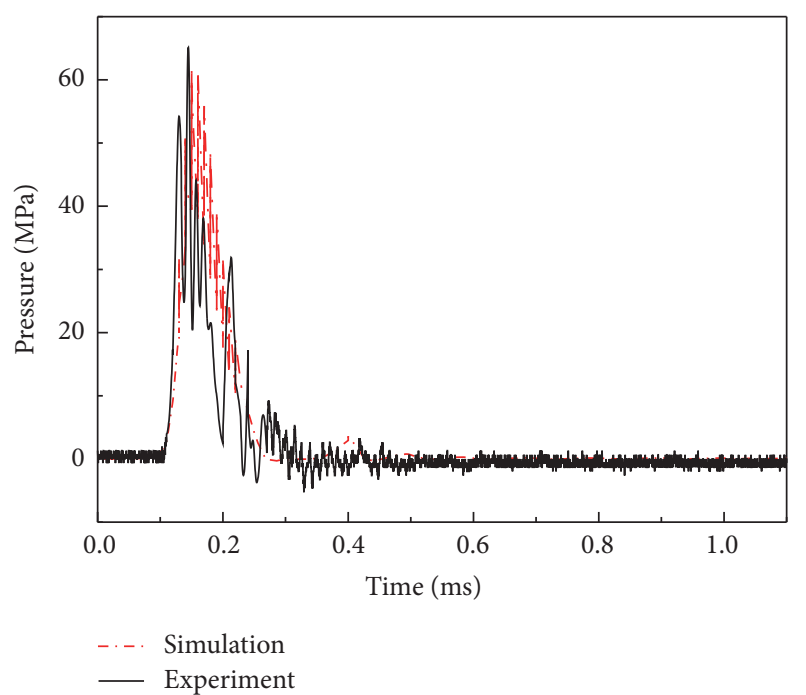

(a)

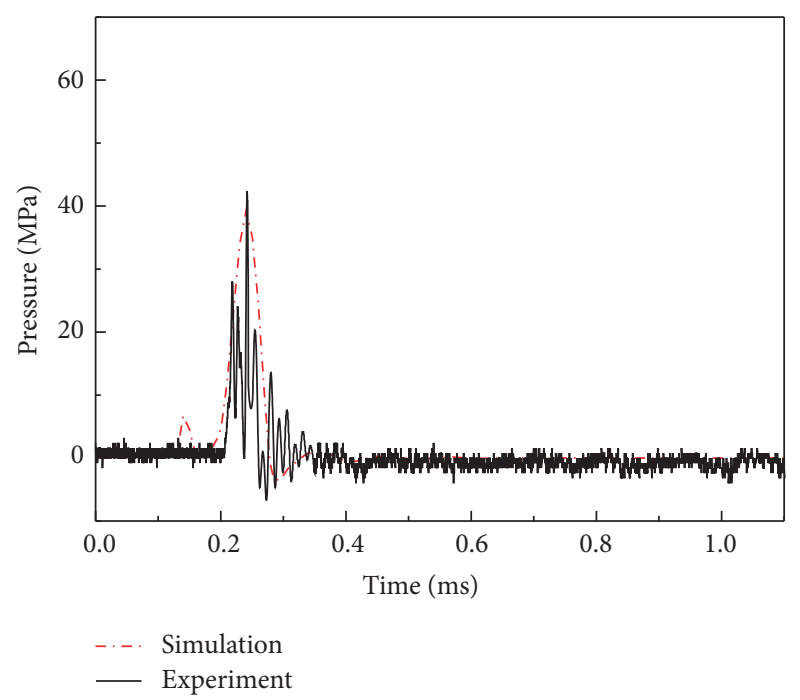

(b)

Figure 10: The pressure-time histories in experiment and simulation. (a) Point B. (b) Point C.

\subsection{Boundary Shear Fracture of Aluminium Foam Panel}

4.1.1. Underwater Pressure-Time History. In order to study the influence of underwater shock wave on target board, a comparative analysis of pressure-time history of shock wave measured through experiment and simulation was implemented. The thickness of flyer used in the experiment was $5 \mathrm{~mm}$. Its speed was $v_{1}=135.06 \mathrm{~m} / \mathrm{s}$. The starting point of time was the moment when flyer impacted piston.

As point A was too close to the piston, it was easy for sensor at point $A$ to be damaged and the measurement results might be inaccurate. Hence, the pressure-time histories at points $\mathrm{B}$ and $\mathrm{C}$ were compared. The pressure-time histories obtained by experiment and simulation were shown in Figure 10. The curve oscillation obtained by experiment was quite serious while simulation curves were smooth. It is because the viscosity coefficients in the simulation made curves smooth to a certain degree.

According to formula (9), the peak pressures of shock wave at points $\mathrm{B}$ and $\mathrm{C}$ were

$$
\begin{aligned}
& p_{B}=\left(\frac{D_{0}}{D_{B}}\right)^{2} \frac{\left(\rho_{0} C_{0}\right)_{1}\left(\rho_{0} C_{0}\right)_{2}}{\left(\rho_{0} C_{0}\right)_{1}+\left(\rho_{0} C_{0}\right)_{2}} v_{1}=73.8 \mathrm{MPa} \\
& p_{C}=\left(\frac{D_{0}}{D_{C}}\right)^{2} \frac{\left(\rho_{0} C_{0}\right)_{1}\left(\rho_{0} C_{0}\right)_{2}}{\left(\rho_{0} C_{0}\right)_{1}+\left(\rho_{0} C_{0}\right)_{2}} v_{1}=41.1 \mathrm{MPa},
\end{aligned}
$$

where $D_{0}=66 \mathrm{~mm}, D_{B}=106 \mathrm{~mm}, D_{C}=142 \mathrm{~mm},\left(\rho_{0} C_{0}\right)_{1}=$ $1.46 \times 10^{6} \mathrm{~kg} /\left(\mathrm{s} \cdot \mathrm{m}^{2}\right)$, and $\left(\rho_{0} C_{0}\right)_{2}=40.82 \times 10^{6} \mathrm{~kg} /\left(\mathrm{s} \cdot \mathrm{m}^{2}\right)$.

Peak pressures obtained by theory, simulation, and experiment were listed in Table 3.

It could be seen from Table 1 that the deviation among theoretical value, simulation value, and experiment value was small. The shock wave pressure at an arbitrary point in the water tank could be predicted through theoretical formula.

\begin{tabular}{|c|c|c|c|}
\hline \multicolumn{4}{|c|}{ Theoretical value/MPa Experiment/MPa Simulation/MPa } \\
\hline Point B & 73.8 & 65.1 & 61.4 \\
\hline Point $\mathrm{C}$ & 41.1 & 42.4 & 39.2 \\
\hline
\end{tabular}

TABLE 3: The peak pressure of shock wave.

4.1.2. Damage Analysis of Boundary Shear Fracture. Realtime deformation of front face sheet measured by VIC-3D was shown in Figure 11. Figures 11(a)-11(d) were deformation moiré patterns when boundary shear fracture did not happen. It could be seen that when front face sheet was in deformation, the region with the maximum deformation moved from all round to the center. After deformation became stable, deformation of the center region was the maximum. Later on, the region with the maximum deformation moved from the center to the left side, which indicated that, at the moment, left side of front face sheet generated boundary shear fracture. It was shown in Figures 11(e) and 11(f).

Shapes of aluminium foam panel, front face sheet (carrying speckles), and back face sheet after impact obtained from the experiment were shown in Figure 12.

It could be seen that both aluminium foam panel and front face sheet generated boundary shear fracture, while back face sheet did not. The constraint of inner-diameter boundary of flange resulted in that aluminium foam panel and front face sheet generated boundary shear fracture. The energy absorption performance of aluminium foam panel had buffering effect on back face sheet, so the back face sheet only experienced plastic deformation but was not damaged.

The deformation and stress diagrams of aluminium foam panel after damage obtained by simulation were shown in Figure 13. By comparing with Figure 12(a), it could be known that simulation could simulate its damage pattern well. It could be known from Figure 13(b) that stress concentration 


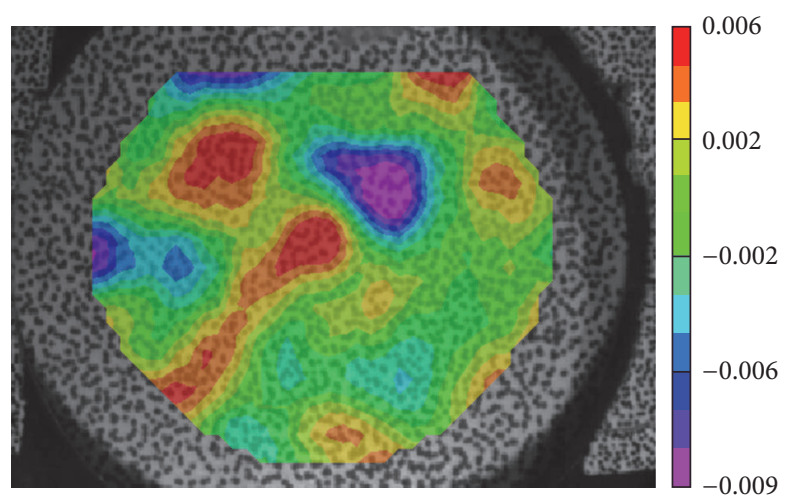

(a)

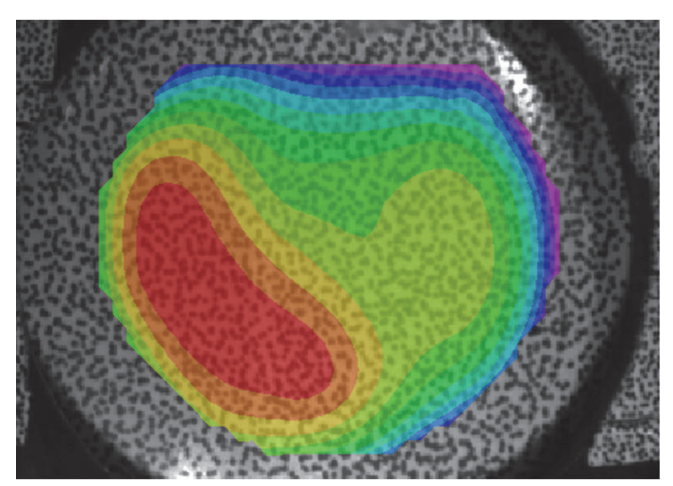

(c)

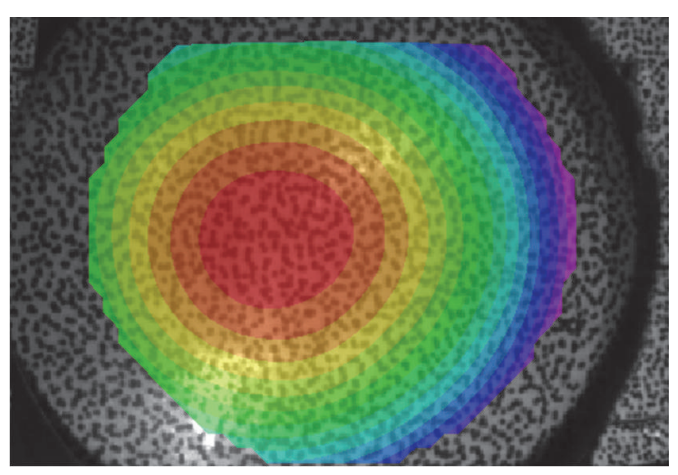

(e)

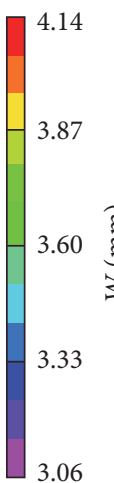

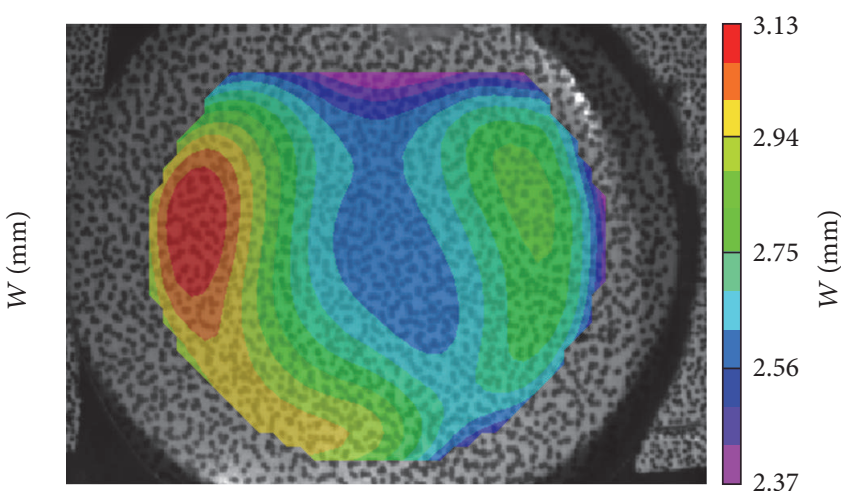

(b)

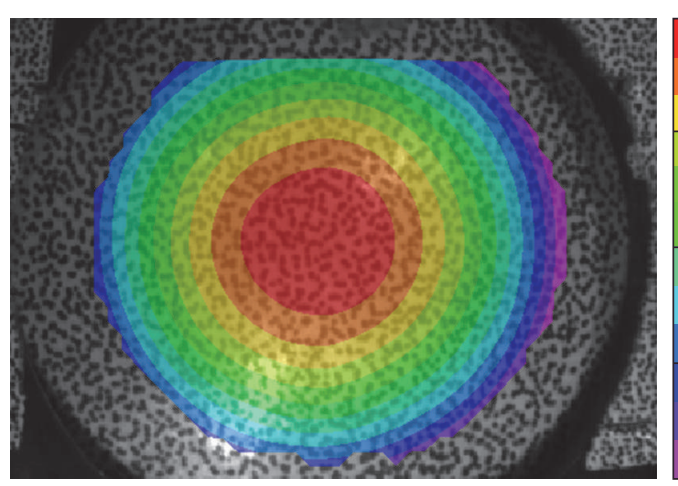

19.00

16.39

$13.77 \underset{\Xi}{\Xi}$

11.16

8.55

(d)
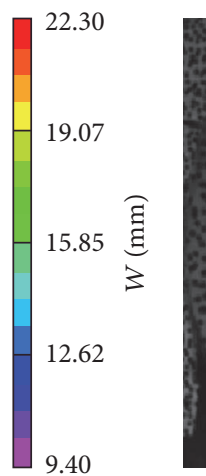

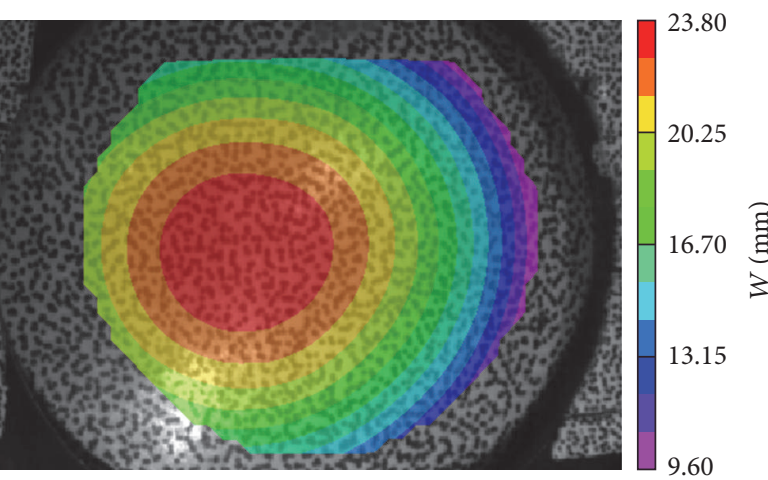

(f)

Figure 11: The real-time deformation of front face sheet calculating by VIC-3D. (a) $t=0 \mathrm{~ms}$; (b) $t=0.7 \mathrm{~ms}$; (c) $t=0.74 \mathrm{~ms}$; (d) $t=1.5 \mathrm{~ms}$; (e) $t=2 \mathrm{~ms}$; and (f) $t=3 \mathrm{~ms}$.

generated at constrained boundary of flange, and, consequently, shear fracture occurred at the boundary.

Taking central point of front face sheet as original point, deformation curves of front face sheet along radial direction (direction $x$ ) at different moments were shown in Figure 14. It is noteworthy that the curves were plotted from -50 to $50 \mathrm{~mm}$, while the boundaries were located at -76 and $76 \mathrm{~mm}$. The operation mode of speckle method made it impossible to calculate the deformation at boundaries.

Solid line in Figure 14 represented the moment when the front face sheet did not generate boundary shear fracture, and dashed line represented the moment after the front face sheet generated boundary shear fracture. It could be obtained from Figure 14 that before $1.5 \mathrm{~ms}$, the front face sheet was not damaged, the position with the maximum deformation was central position, and the maximum deformation was $19.12 \mathrm{~mm}$; after $1.5 \mathrm{~ms}$, left side of the front face sheet generated boundary shear fracture and tilted, so the position with the maximum deformation moved towards left and the maximum deformation was $23.82 \mathrm{~mm}$ after stabilization.

4.1.3. Energy. Kinetic energy and internal energy histories of aluminium foam panel per unit mass obtained from simulation were shown in Figure 15. When shock wave reached aluminium foam panel, kinetic energy and internal 


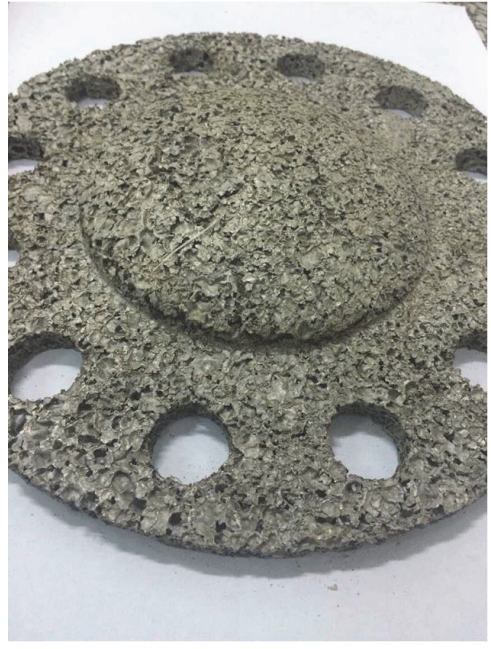

(a)

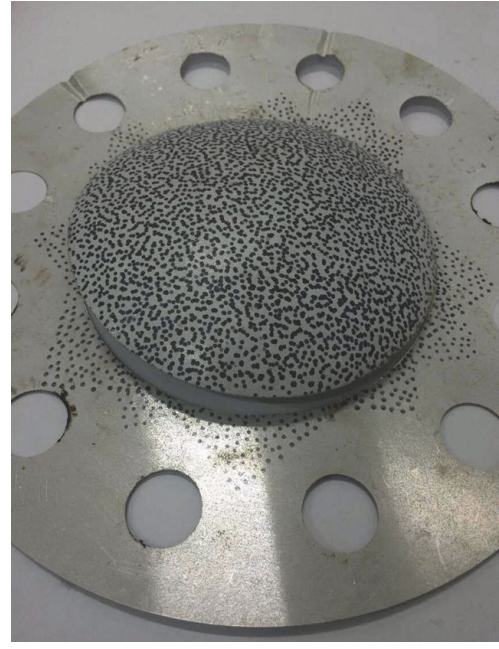

(b)

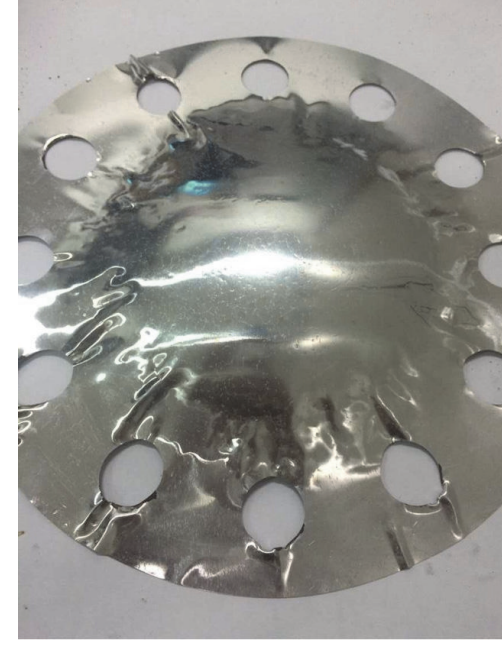

(c)

Figure 12: The shape of the target board after impacting. (a) Aluminium foam. (b) Front face sheet. (c) Back face sheet.

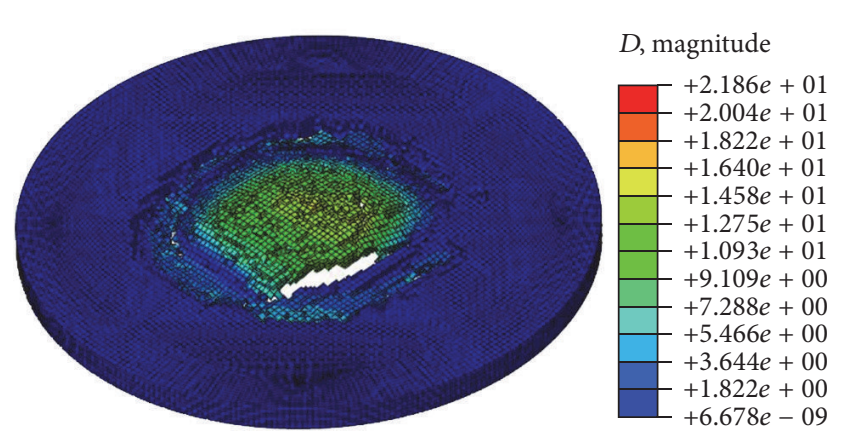

(a)

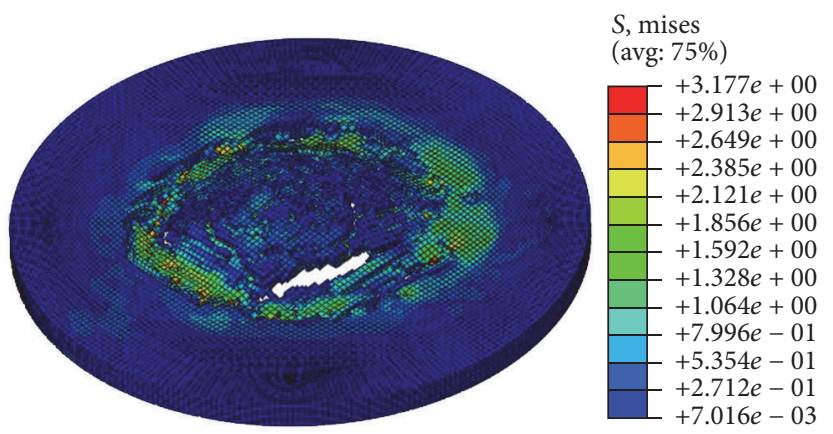

(b)

FIGURE 13: The moire pictures of damaged aluminium foam panel in ABAQUS. (a) Figure of deformation. (b) Figure of stress.

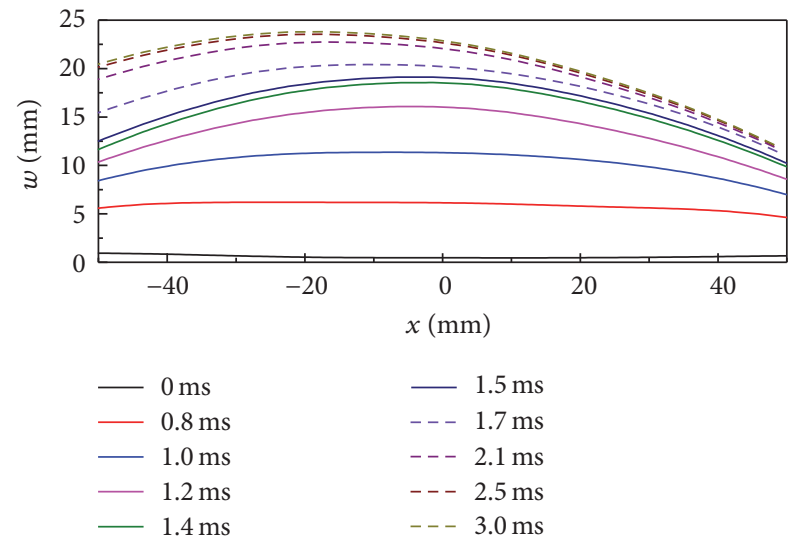

FIGURE 14: The radial deformation curves of the front face sheet.

energy abruptly increased. Then kinetic energy decreased while internal energy slowly increased.

\subsection{Central Fracture of Aluminium Foam Panel}

4.2.1. Underwater Pressure-Time History. The thickness of flyer used in the experiment was still $5 \mathrm{~mm}$, and its speed was $v_{1}=153.33 \mathrm{~m} / \mathrm{s}$. The starting point of time was the moment when flyer impacted piston. The pressure-time histories of points $\mathrm{B}$ and $\mathrm{C}$ obtained from experiment and simulation were shown in Figure 16. According to formula (9), the peak pressures of shock wave at points $\mathrm{B}$ and $\mathrm{C}$ could be obtained, respectively, as

$$
\begin{aligned}
& p_{B}=\left(\frac{D_{0}}{D_{B}}\right)^{2} \frac{\left(\rho_{0} C_{0}\right)_{1}\left(\rho_{0} C_{0}\right)_{2}}{\left(\rho_{0} C_{0}\right)_{1}+\left(\rho_{0} C_{0}\right)_{2}} v_{1}=83.8 \mathrm{MPa} \\
& p_{C}=\left(\frac{D_{0}}{D_{C}}\right)^{2} \frac{\left(\rho_{0} C_{0}\right)_{1}\left(\rho_{0} C_{0}\right)_{2}}{\left(\rho_{0} C_{0}\right)_{1}+\left(\rho_{0} C_{0}\right)_{2}} v_{1}=46.7 \mathrm{MPa}
\end{aligned}
$$

Peak pressures obtained from theory, simulation, and experiment were listed in Table 4. 


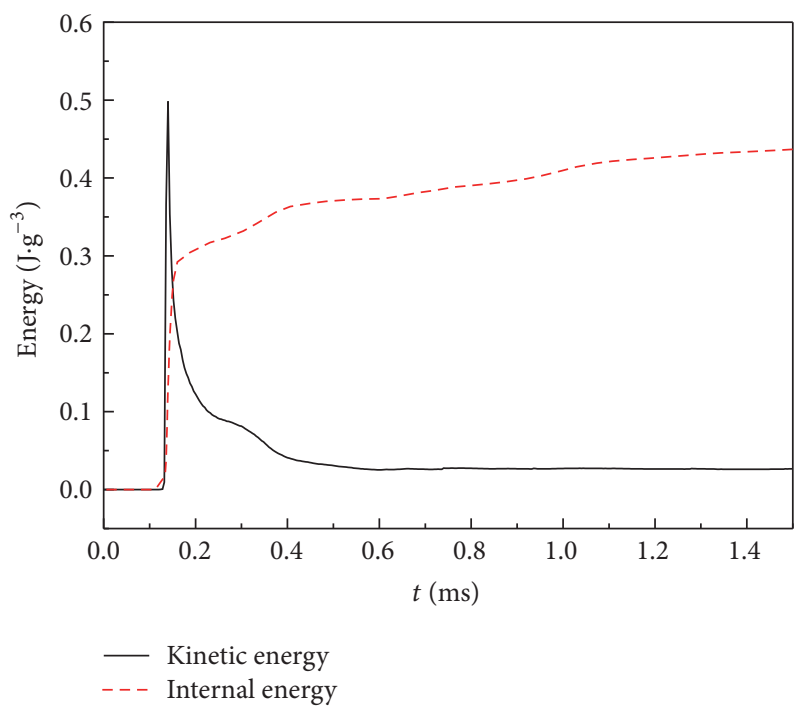

FIGURE 15: The energy-time history in simulation.

TABLE 4: The peak pressure of shock wave.

\begin{tabular}{|c|c|c|c|}
\hline \multicolumn{4}{|c|}{ Theoretical value/MPa Experiment/MPa Simulation/MPa } \\
\hline Point B & 83.8 & 74.2 & 70.0 \\
\hline Point C & 46.7 & 45.6 & 44.7 \\
\hline
\end{tabular}

It could be seen from Table 4 that theoretical value, simulation value, and experiment value of peak pressure were still identical.

4.2.2. Damage Analysis of Central Fracture. After front face sheet generated central fracture, the speckles could not be recognized and calculated by VIC-3D software. So the realtime deformation could be measured only before central fracture was generated. It was shown in Figure 17. After central fracture, original photographs of front face sheet were shown in Figure 18.

It could be seen that when the front face sheet was under deformation, the region with maximum deformation would still move from all round to the center. After deformation became stable, deformation in the central region was the maximum. Later on, the aluminium foam panel firstly generated fracture at the center and then generated shear fracture at constrained boundary of flange.

In order to verify results observed from the experiment, deformation and stress diagrams of aluminium foam panel at $0.76 \mathrm{~ms}$ and $2 \mathrm{~ms}$ in simulation were chosen as shown in Figure 19. It could be seen that aluminium foam panel only generated central fracture at $0.76 \mathrm{~ms}$; central fracture and boundary shear fracture simultaneously existed at $2 \mathrm{~ms}$. It indicated that aluminium foam panel firstly generated central fracture and then generated boundary shear fracture. It was identical with experimental results.

It could be known from Figures 19(c) and 19(d) that stress concentration was generated at the place where central fracture and boundary shear fracture occurred or the constrained boundary of flange.

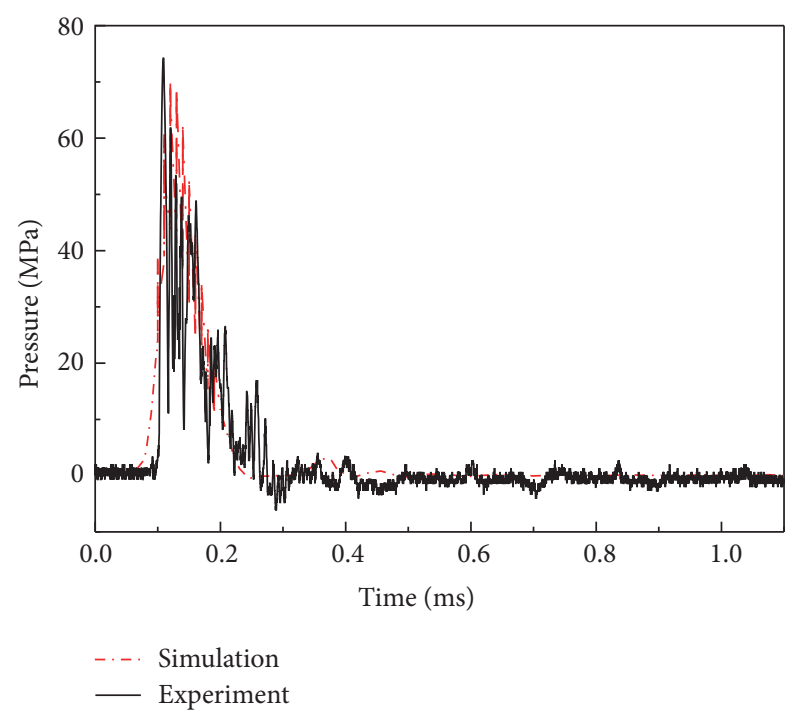

(a)

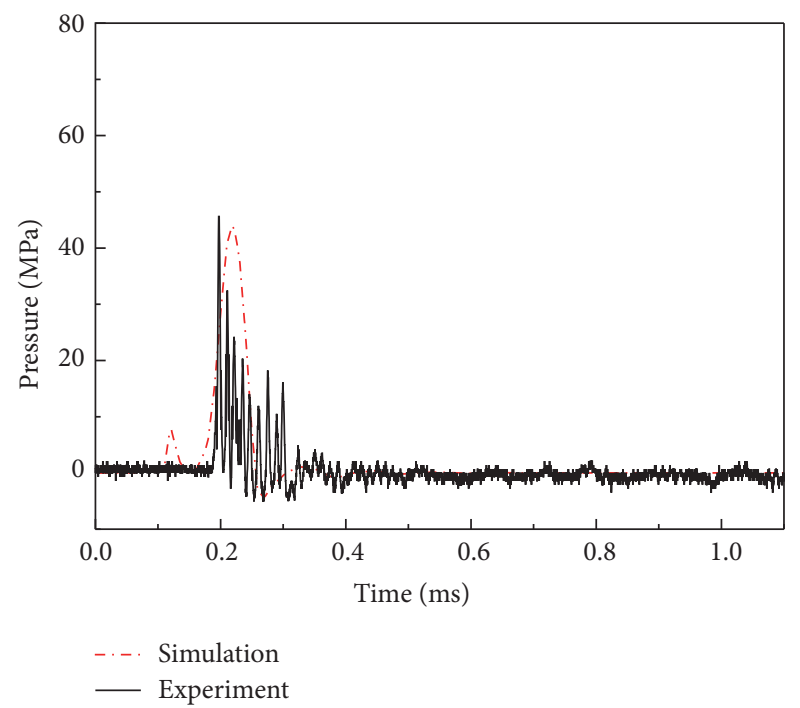

(b)

FIGURE 16: The pressure-time histories in experiment and simulation. (a) Point B. (b) Point C.

After impacting, shapes of aluminium foam panel, front face sheet, and back face sheet were shown in Figure 20.

It could be known that aluminium foam panel, front face sheet, and back face sheet all generated central fracture and boundary shear fracture. By comparing Figure 19(c) with Figure 20(a), it could be known that the simulation could simulate the damage modes of central fracture and boundary shear fracture very well. After damage, central region of the aluminium foam panel generated three obvious cracks, which was identical with the experimental results (in the experiment, one region divided by three cracks fell off).

Taking central point of front face sheet as original point, deformation curves of front face sheet along radial direction (direction $x$ ) at different moments were shown in Figure 21. The curves were still plotted from -50 to $50 \mathrm{~mm}$. When $t=$ $1.2 \mathrm{~ms}$, the speckles at the center could not be measured or 


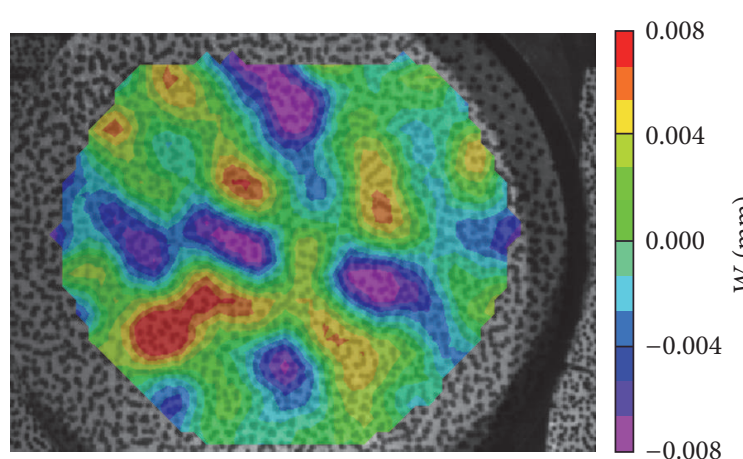

(a)

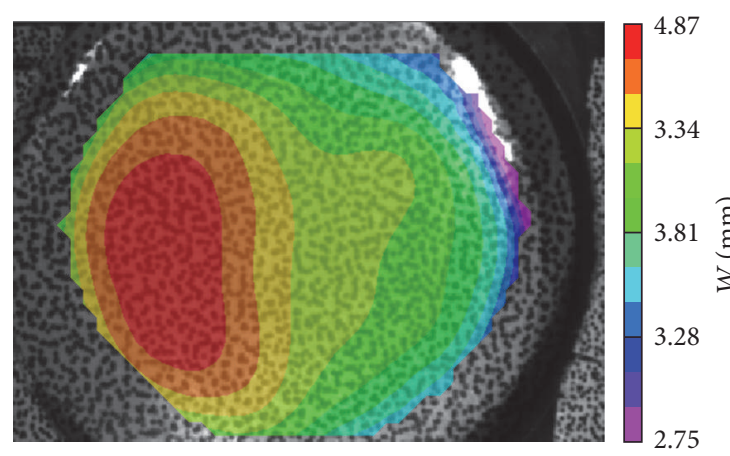

(c)

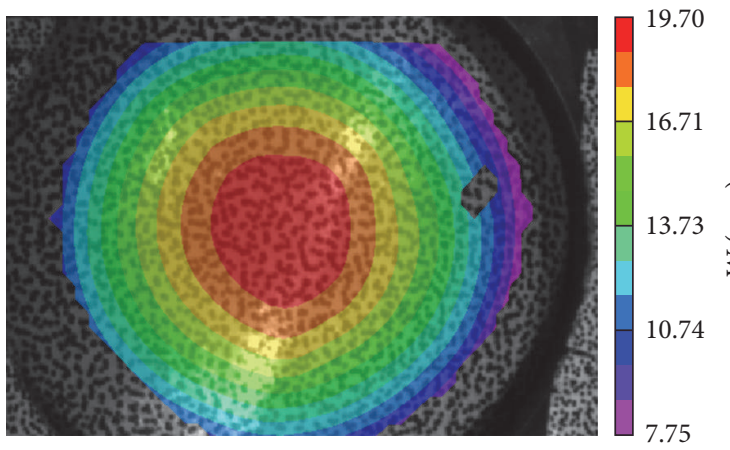

(e)

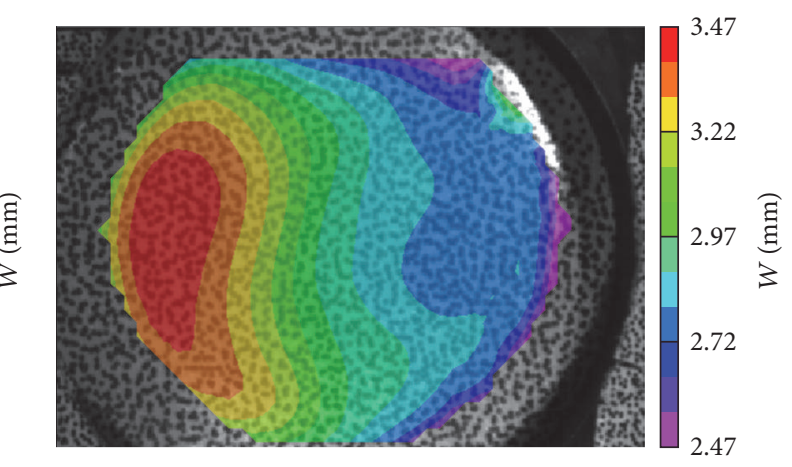

(b)

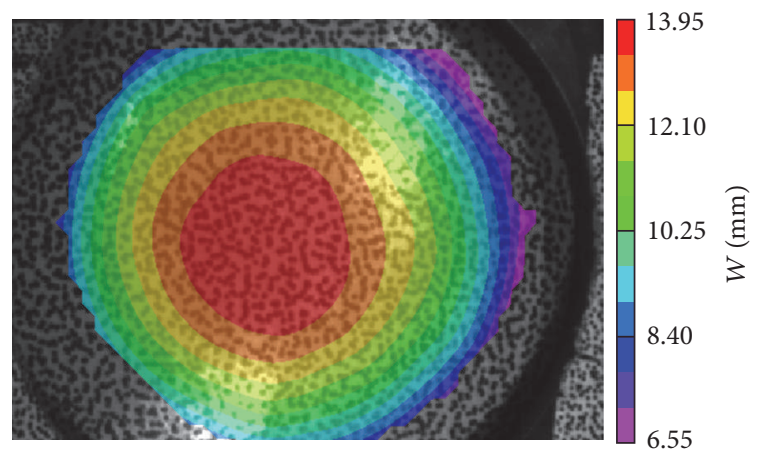

(d)

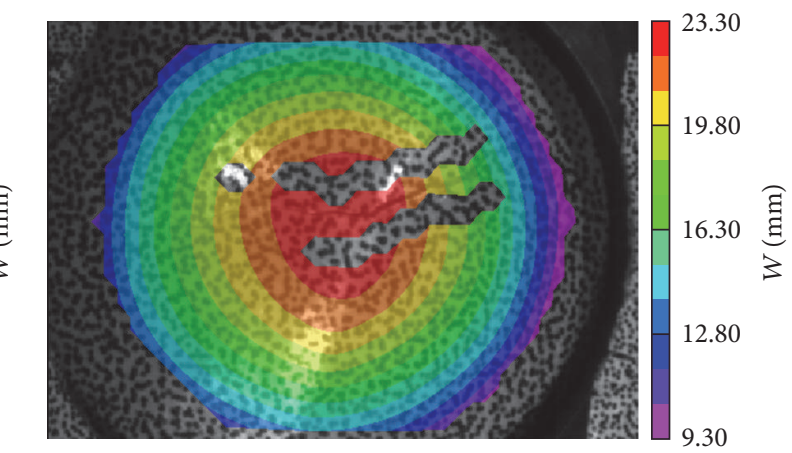

(f)

Figure 17: The real-time deformation of front face sheet calculating by VIC-3D. (a) $t=0 \mathrm{~ms}$; (b) $t=0.46 \mathrm{~ms}$; (c) $t=0.5 \mathrm{~ms}$; (d) $t=0.8 \mathrm{~ms}$; (e) $t=1 \mathrm{~ms}$; and (f) $t=1.18 \mathrm{~ms}$.

calculated as central fracture was generated. So there was a part of blank curve. The maximum deformation of front face sheet before it was damaged was $23.32 \mathrm{~mm}$.

From above analysis, it could be speculated that maximum deformations of the same aluminium foam before the center fracture was generated were the same in different damage modes. The maximum deformation of this aluminium foam panel was $23 \sim 24 \mathrm{~mm}$.

4.2.3. Energy. Kinetic energy and internal energy histories of aluminium foam panel per unit mass obtained from simulation were shown in Figure 22. The variation tendency of kinetic energy and internal energy was identical with that when aluminium foam panel generated boundary shear fracture. The maximum value of kinetic energy was greater than that of boundary shear fracture. Final internal energy was identical with that of boundary shear fracture, which indicated that the energy absorbed by aluminium foam panel was the same in two cases.

\section{Conclusion}

Through underwater shock loading experiment device, the damage modes of aluminium foam panel subjected to underwater shock loading were studied. 3D dynamic DIC test system was used to measure full-field deformation of aluminium foam panel. Then ABAQUS finite element software was used to conduct corresponding numerical simulation of the experiment. From the comparison it could be known that 


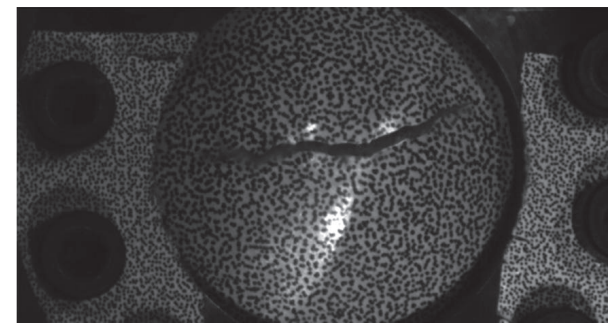

(a)

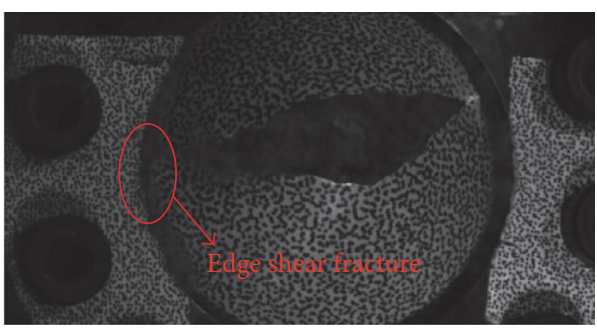

(c)

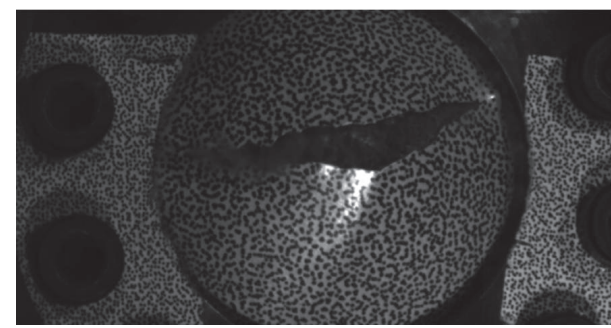

(b)

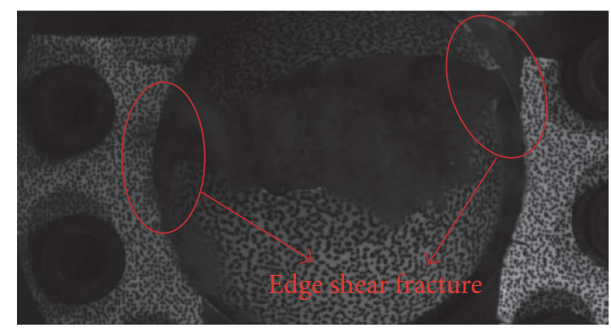

(d)

FIGURE 18: The photographs of front face sheet when they were damaged. (a) $t=1.4 \mathrm{~ms}$; (b) $t=1.8 \mathrm{~ms}$; (c) $t=2.4 \mathrm{~ms}$; and (d) $t=3.4 \mathrm{~ms}$.

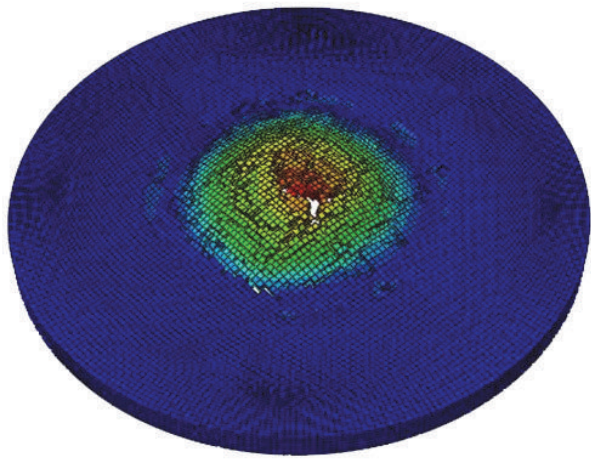

(a)

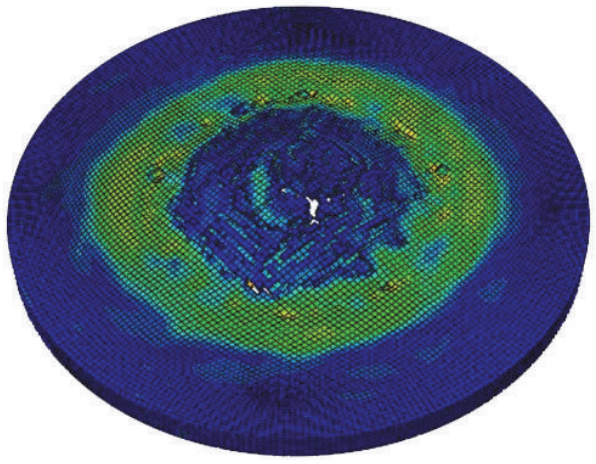

(c)
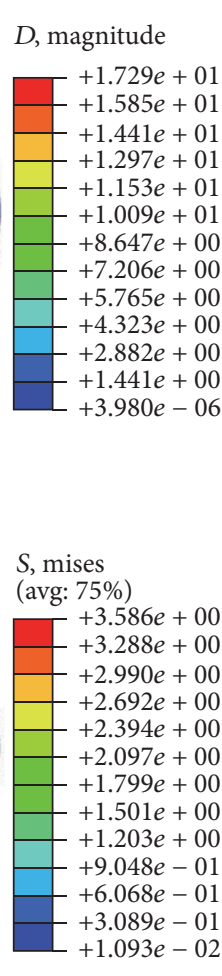

$+1.093 e-02$

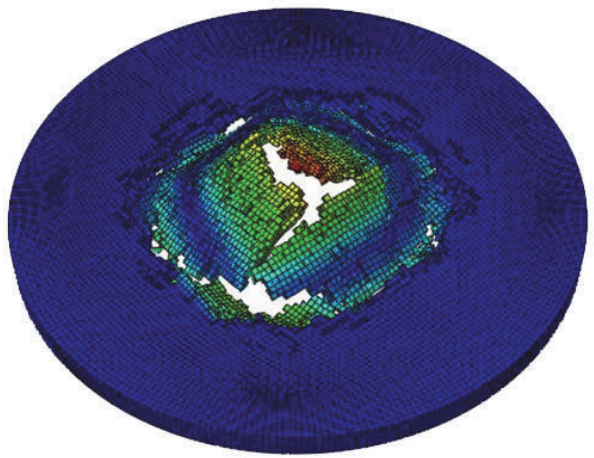

(b)

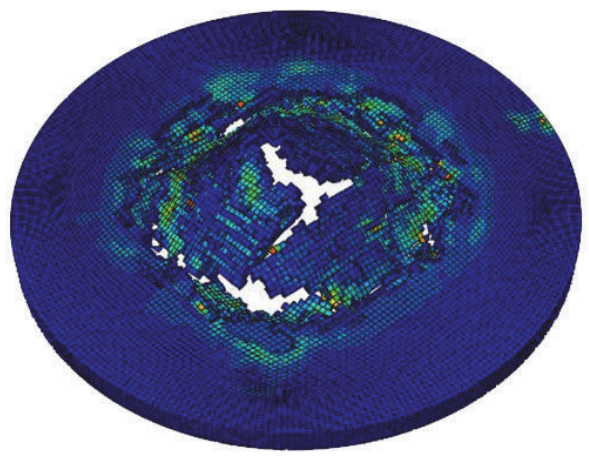

(d)
$S$, mises (avg: 75\%)

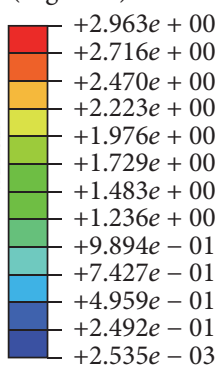

$D$, magnitude

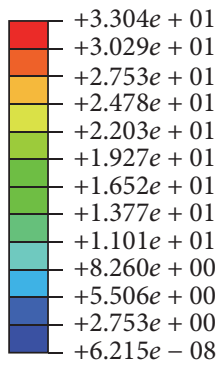

$+2.535 e-03$

Figure 19: The moire pictures of damaged aluminium foam panel in ABAQUS. (a) Figure of displacement when $t=0.76 \mathrm{~ms}$. (b) Figure of displacement when $t=2 \mathrm{~ms}$. (c) Figure of stress when $t=0.76 \mathrm{~ms}$. (d) Figure of stress when $t=2 \mathrm{~ms}$. 


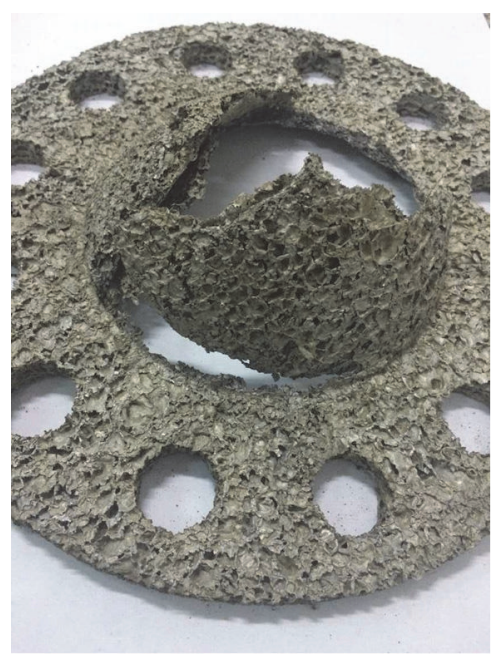

(a)

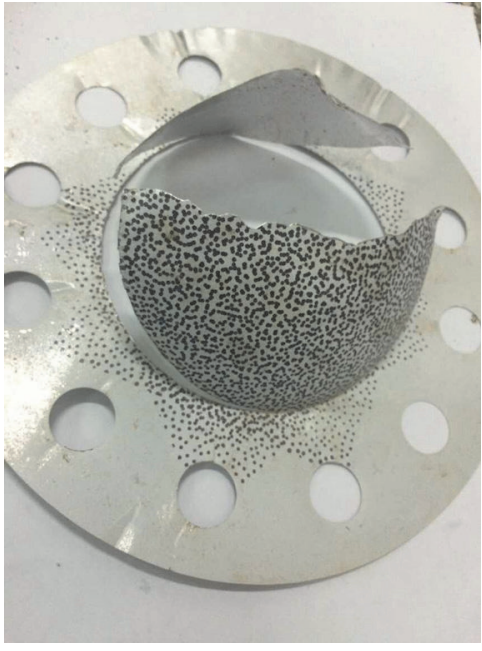

(b)

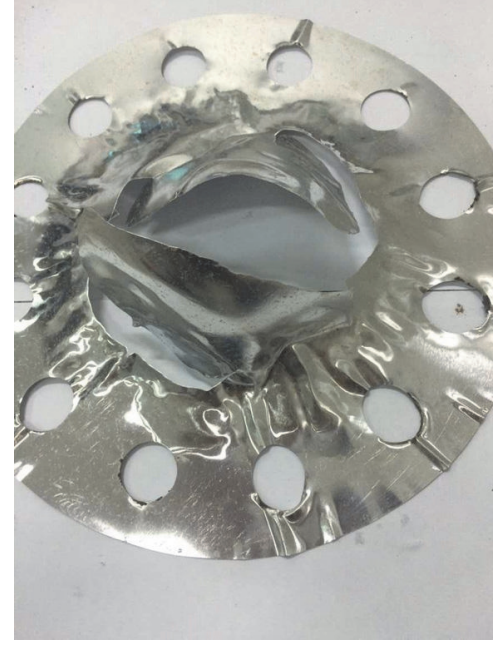

(c)

FIgURE 20: The shape of the target board after impact. (a) Aluminium foam. (b) Front face sheet. (c) Back face sheet.

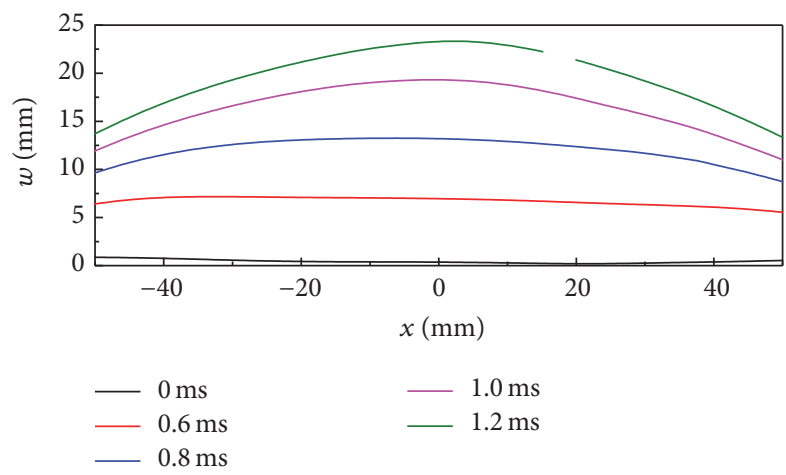

FIGURE 21: The radial deformation curve of the front face sheet.

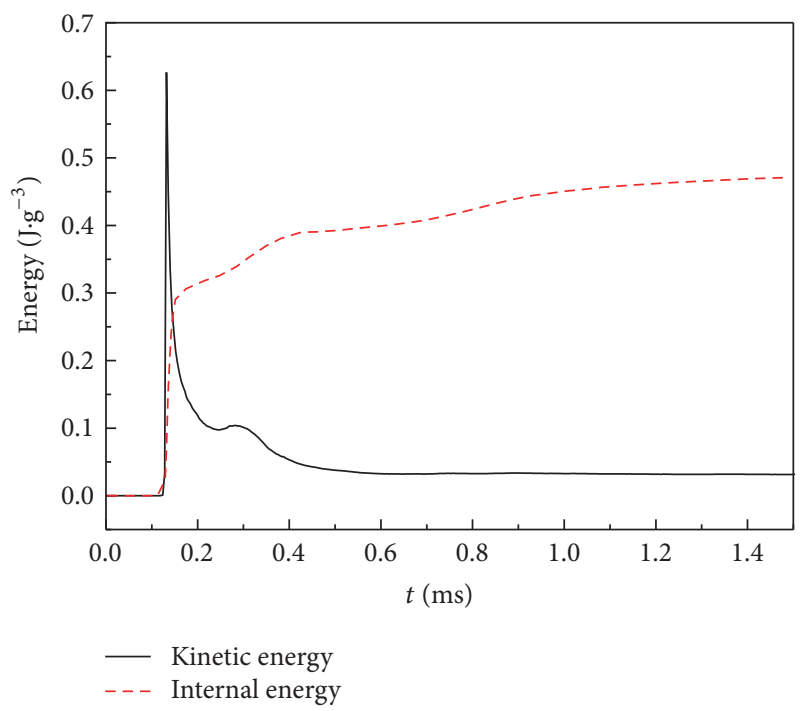

FIGURE 22: The energy-time history in simulation. the simulation could simulate two different damage modes of aluminium foam panel very well. Results indicated that

(a) there were two damage modes of aluminium foam panel. When a certain impact speed which could make the aluminium foam panel be damaged was reached, if the impact speed was low, aluminium foam panel would generate shear fracture at constrained boundary of flange; if the impact speed was high, aluminium foam panel would firstly generate fracture at the center and then generate shear fracture at constrained boundary of flange, and central fracture would generate three cracks;

(b) whether the damage mode of the aluminium foam panel was boundary shear fracture or central fracture, the maximum deformation of aluminium foam panel before central region was damaged was the same. The maximum deformation of this kind of aluminium foam panel (density was $0.3 \mathrm{~g} / \mathrm{cm}^{3}$ ) was $23 \sim 24 \mathrm{~mm}$;

(c) the energy absorbed by the same aluminium foam panel was the same in two damage modes;

(d) when aluminium foam panel only generated boundary shear fracture, it had buffer function on the back face sheet. As a result, the back face sheet only generated deformation but was not damaged.

\section{Competing Interests}

The authors declare that they have no competing interests.

\section{Acknowledgments}

This research was supported by the Joint Fund of the National Natural Science Foundation of China and the 
China Academy of Engineering Physics (NSAF) (Grant no. U1530147) and the National Natural Science Foundation of China (Project nos. 11502021 and 11272057).

\section{References}

[1] V. Rizov, A. Shipsha, and D. Zenkert, "Indentation study of foam core sandwich composite panels," Composite Structures, vol. 69, no. 1, pp. 95-102, 2005.

[2] Z. K. Liu, Y. L. Young, and M. R. Motley, “Transient response of partially-bonded sandwich plates subject to underwater explosions," Shock and Vibration, vol. 17, no. 3, pp. 233-250, 2010.

[3] M. A. Yahaya, D. Ruan, G. Lu, and M. S. Dargusch, "Response of aluminium honeycomb sandwich panels subjected to foam projectile impact-an experimental study," International Journal of Impact Engineering, vol. 75, pp. 100-109, 2015.

[4] L. Mu and G. Zhao, "Fundamental frequency analysis of sandwich beams with functionally graded face and metallic foam core," Shock and Vibration, vol. 2016, Article ID 3287645 , 10 pages, 2016.

[5] V. S. Deshpande and N. A. Fleck, "High strain rate compressive behaviour of aluminum alloy foams," International Journal of Impact Engineering, vol. 24, no. 3, pp. 277-298, 2000.

[6] V. S. Deshpande and N. A. Fleck, "Isotropic constitutive models for metallic foams," Journal of the Mechanics and Physics of Solids, vol. 48, no. 6, pp. 1253-1283, 2000.

[7] T. Mukai, H. Kanahashi, T. Miyoshi, M. Mabuchi, T. G. Nieh, and K. Higashi, "Experimental study of energy absorption in a close-celled aluminum foam under dynamic loading," Scripta Materialia, vol. 40, no. 8, pp. 921-927, 1999.

[8] A. Paul and U. Ramamurty, "Strain rate sensitivity of a closedcell aluminum foam," Materials Science and Engineering A, vol. 281, no. 1-2, pp. 1-7, 2000.

[9] K. A. Dannemann and J. Lankford Jr., "High strain rate compression of closed-cell aluminum foams," Materials Science and Engineering A, vol. 293, no. 1, pp. 157-164, 2000.

[10] D. D. Radford, G. J. McShane, V. S. Deshpande, and N. A. Fleck, "The response of clamped sandwich plates with metallic foam cores to simulated blast loading," International Journal of Solids and Structures, vol. 43, no. 7-8, pp. 2243-2259, 2006.

[11] V. S. Deshpande, A. Heaver, and N. A. Fleck, "An underwater shock simulator," Proceedings of the Royal Society A: Mathematical, Physical and Engineering Sciences, vol. 462, no. 2067, pp. 1021-1041, 2006.

[12] V. S. Deshpande and N. A. Fleck, "One-dimensional response of sandwich plates to underwater shock loading," Journal of the Mechanics and Physics of Solids, vol. 53, no. 11, pp. 2347-2383, 2005.

[13] H. D. Espinosa, S. Lee, and N. Moldovan, "A novel fluid structure interaction experiment to investigate deformation of structural elements subjected to impulsive loading," Experimental Mechanics, vol. 46, no. 6, pp. 805-824, 2006.

[14] L. F. Mori, D. T. Queheillalt, H. N. G. Wadley, and H. D. Espinosa, "Deformation and failure modes of I-core sandwich structures subjected to underwater impulsive loads," Experimental Mechanics, vol. 49, no. 2, pp. 257-275, 2009.

[15] L. F. Mori, S. F. Lee, Z. Y. Xue et al., "Deformation and fracture modes of sandwich structures subjected to underwater impulsive loads," Journal of Mechanics of Materials and Structures, vol. 2, no. 10, pp. 1981-2006, 2007.
[16] F. Latourte, X. Wei, Z. D. Feinberg et al., "Design and identification of high performance steel alloys for structures subjected to underwater impulsive loading," International Journal of Solids and Structures, vol. 49, no. 13, pp. 1573-1587, 2012.

[17] F. Latourte, D. Grégoire, D. Zenkert, X. Wei, and H. D. Espinosa, "Failure mechanisms in composite panels subjected to underwater impulsive loads," Journal of the Mechanics and Physics of Solids, vol. 59, no. 8, pp. 1623-1646, 2011.

[18] X. Wei, P. Tran, A. de Vaucorbeil, R. Bellur Ramaswamy, F. Latourte, and H. D. Espinosa, "Three-dimensional numerical modeling of composite panels subjected to underwater blast," Journal of the Mechanics and Physics of Solids, vol. 61, no. 6, pp. 1319-1336, 2013.

[19] P. Tran, T. D. Ngo, and P. Mendis, "Bio-inspired composite structures subjected to underwater impulsive loading," Computational Materials Science, vol. 82, pp. 134-139, 2014.

[20] D.-L. Xiang, J.-L. Rong, and X. He, "Experimental investigation of dynamic response and deformation of aluminium honeycomb sandwich panels subjected to underwater impulsive loads," Shock and Vibration, vol. 2015, Article ID 650167, 13 pages, 2015.

[21] V. Crupi and R. Montanini, "Aluminium foam sandwiches collapse modes under static and dynamic three-point bending," International Journal of Impact Engineering, vol. 34, no. 3, pp. 509-521, 2007.

[22] G. S. Langdon, D. Karagiozova, M. D. Theobald, G. N. Nurick, G. Lu, and R. P. Merrett, "Fracture of aluminium foam core sacrificial cladding subjected to air-blast loading," International Journal of Impact Engineering, vol. 37, no. 6, pp. 638-651, 2010.

[23] H. Wang and X. Zha, "Dynamic mechanical behavior and constitutive model of 3004 aluminum," Journal of Huazhong University of Science and Technology, vol. 39, no. 5, pp. 39-42, 2011 (Chinese).

[24] Z. Xue and J. W. Hutchinson, "A comparative study of impulseresistant metal sandwich plates," International Journal of Impact Engineering, vol. 30, no. 10, pp. 1283-1305, 2004. 


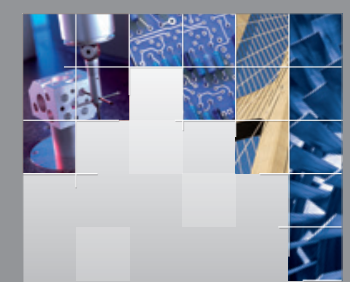

\section{Enfincering}
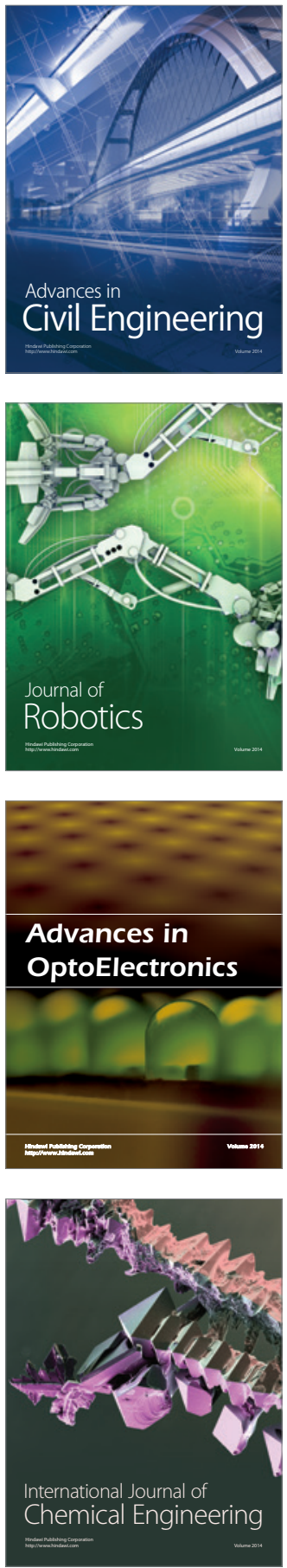

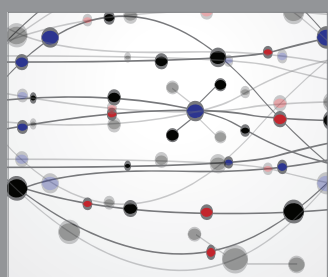

The Scientific World Journal

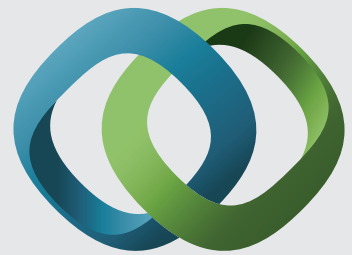

\section{Hindawi}

Submit your manuscripts at

https://www.hindawi.com
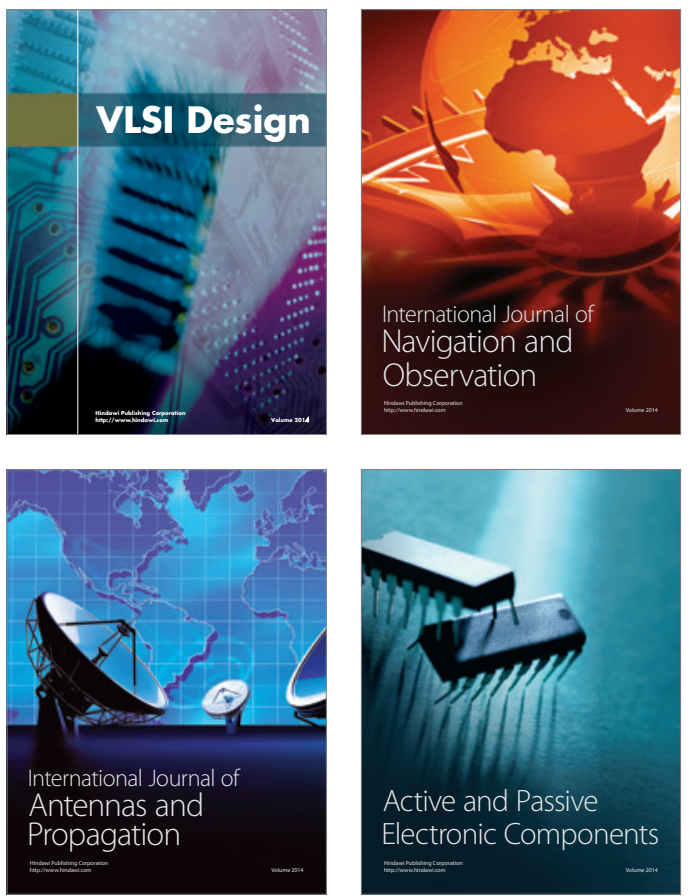
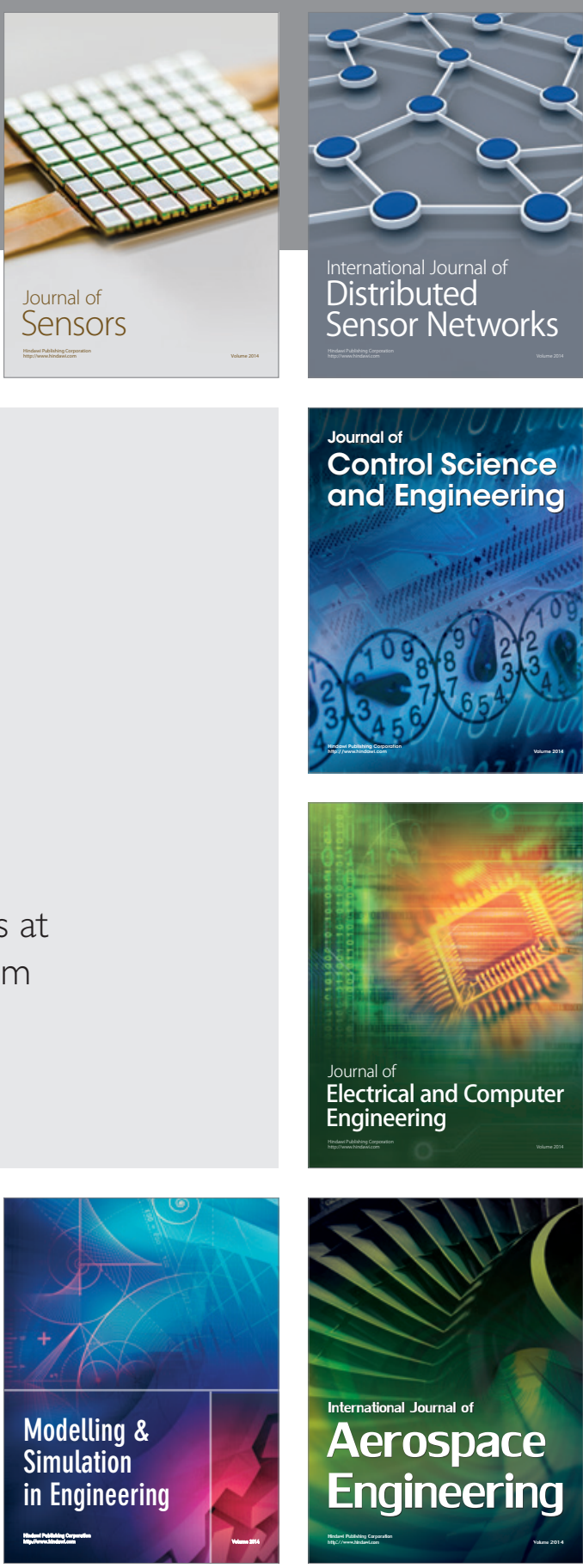

International Journal of

Distributed

Sensor Networks

$-$

Joumal of

Control Science

and Engineering
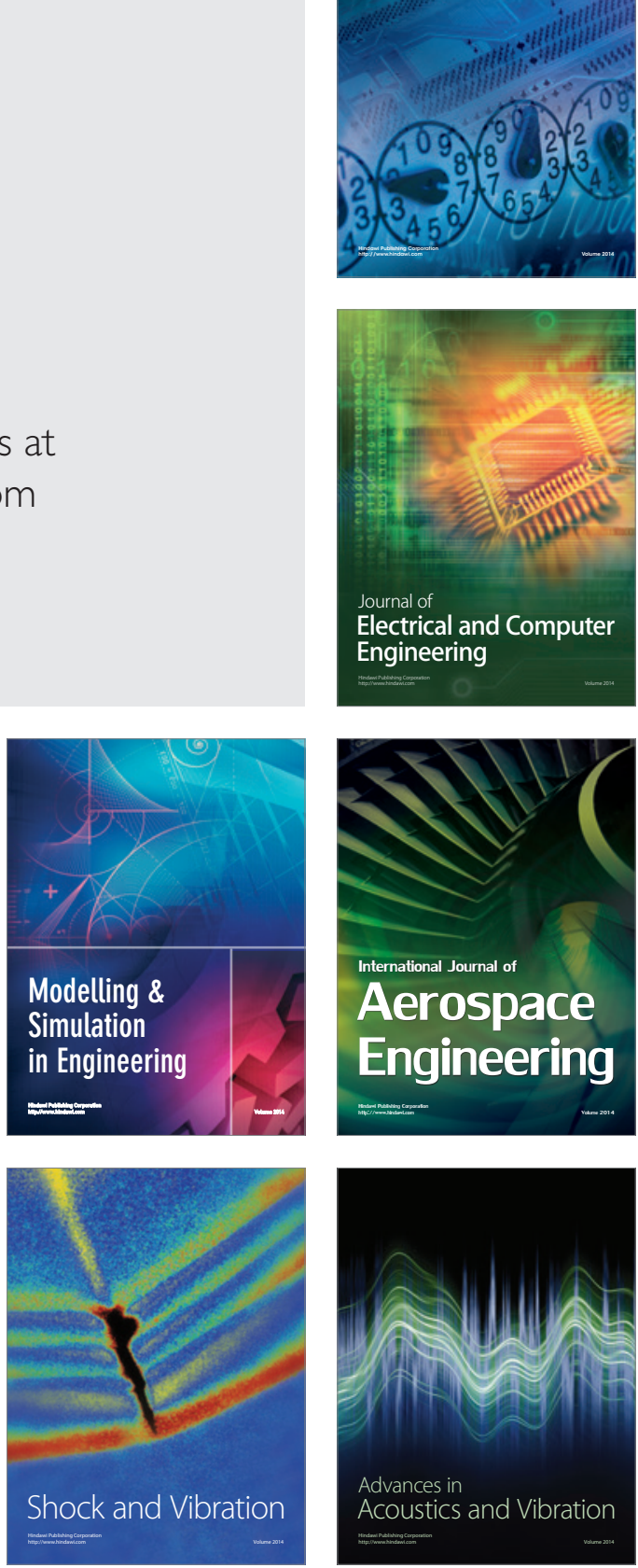